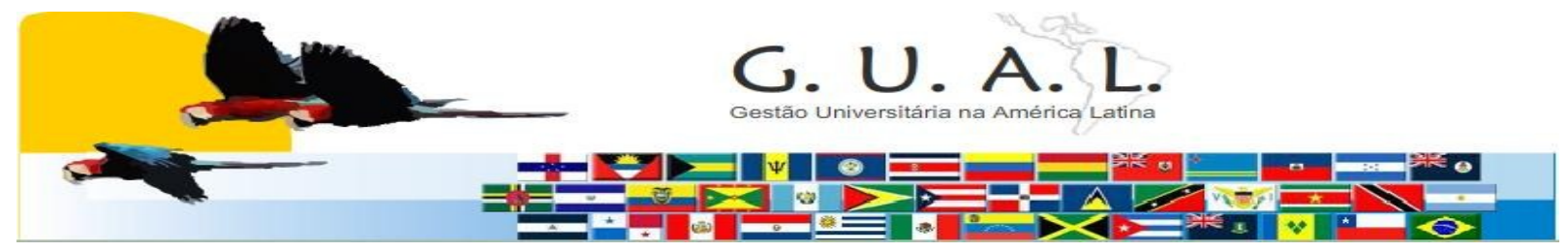

ISSN 1983-4535

\title{
A DEGRADAÇÃO AMBIENTAL NA PERCEPÇÃO DOS ACADÊMICOS DE UM CURSO DE ADMINISTRAÇÃO - UMA LEITURA DO DISCURSO A PRAXIS
}

\author{
Jucelia Appio Tibola, Mestre \\ Universidade Positivo - UP \\ juceliaappio@yahoo.com.br
}

Marialva Tomio Dreher, Doutora

Universidade Regional de Blumenau - FURB

marialva@furb.br

Paula Regina Zarelli Rocha, Especialista

Universidade Estadual do Oeste do Paraná - UNIOESTE

przarelli@hotmail.com

\section{RESUMO}

Neste artigo objetiva-se conhecer a percepção dos acadêmicos do curso de Administração da Universidade Paranaense (UNIPAR), de Francisco Beltrão/PR, em relação à degradação ambiental do município e identificar disciplinas e conteúdos que os sensibilizam para a importância do tema. Para tanto, consultou-se os planos de ensino e aplicou-se um questionário a 201 acadêmicos do supracitado curso. Constatou-se que, por um lado, a maioria dos acadêmicos preserva o pensamento tradicional de que o Estado é responsável pela preservação ambiental, por outro, considera a sociedade em geral como principal responsável pela degradação. Observou-se, ainda, que o currículo do curso precisa ampliar a discussão de assuntos relacionados à gestão ambiental, desenvolvimento sustentável, responsabilidade social e demais assuntos condizentes com a realidade contemporânea.

Palavras-chave: Meio ambiente. Curso de administração. Gestão ambiental. 


\section{A DEGRADAÇÃO AMBIENTAL NA PERCEPÇÃO DOS ACADÊMICOS DE UM CURSO DE ADMINISTRAÇÃO - UMA LEITURA DO DISCURSO A PRAXIS}

\section{INTRODUÇÃO}

Diante das sérias catástrofes causadas pela depredação do solo, das águas e dos recursos naturais, é crescente a valorização da sociedade pelas organizações que buscam formas de minimizar os impactos de suas atividades sobre o ambiente. Por isso, é essencial que os cursos de ensino superior forneçam subsídios necessários para que o futuro administrador consciente das responsabilidades da empresa para com a comunidade em que está inserida adote procedimentos e tecnologias que favoreçam a gestão ambiental.

Porém, nos cursos de Administração brasileiros poucas disciplinas contemplam temáticas que envolvem o discussão ambiental. Para Capra (2003), o currículo deve associar, sempre que possível, os conteúdos das disciplinas e demais discussões especificas relacionadas aos aspectos e princípios socioambientais.

Esse movimento é fundamental, uma vez que ocorrem muitos impactos que poderiam ser evitados pelas organizações. Segundo o Conselho Nacional do Meio Ambiente (CONAMA), considera-se como impacto ambiental qualquer alteração das propriedades físicas, químicas e biológicas causada por atividades humanas que, direta ou indiretamente, afetam a qualidade dos recursos ambientais (IBAMA, 1986). Diante deste contexto, este estudo analisa o caso do município de Francisco Beltrão/PR, onde há indícios de impactos ambientais devido à configuração do sistema de produção agrícola. Impactos atribuídos ao destino final de resíduos sólidos, desmatamento, escassez de água, estiagens e outros (SEMA, 2008).

Devido a esta problemática e com o objetivo de minimizar tais problemas e promover o bem comum, a Secretaria Municipal de Agricultura e Meio Ambiente aprovou a lei 2891/2002, que regulamenta políticas de conservação, recuperação e preservação do meio ambiente. Esta Lei foi criada como estimulo a discussões sobre os impactos ambientais locais. Assim sendo, numa tentativa de observar o discurso e a pratica da comunidade acadêmica sobre esta problemática, este estudo teve por objetivo conhecer o envolvimento dos acadêmicos do curso de Administração da UNIPAR de Francisco Beltrão/PR em relação à degradação ambiental do município.

Os objetivos específicos foram: (a) identificar disciplinas e conteúdos - ministrados no curso de Administração da UNIPAR - que sensibilizem os acadêmicos para a importância do 


\section{A DEGRADAÇÃO AMBIENTAL NA PERCEPÇÃO DOS ACADÊMICOS DE UM CURSO DE ADMINISTRAÇÃO - UMA LEITURA DO DISCURSO A PRAXIS}

meio ambiente; (b) verificar se os acadêmicos apresentam diferenças de percepção em decorrência do curso e suas praticas pessoais nessa questão.

Este estudo se justifica pela necessidade de verificar como os acadêmicos podem relacionar-se com as demandas locais e ainda provocar uma reflexão sobre o atual estágio ambiental do município e o papel dos futuros administradores em conciliar a eficiência empresarial com a conservação ambiental.

\section{O AMBIENTE, AS EMPRESAS E O ENSINO DE ADMINISTRAÇÃO}

A preocupação ambiental - antes restrita a estudiosos da área e a alguns grupos preservacionistas - tem conquistado espaços importantes no meio social, acadêmico, governamental e empresarial (VARGAS; RIBEIRO, 2002). Vários instrumentos de gestão ambiental vêm discutindo a relação da empresa com o ambiente que abrange o micro e o macroambiente, ou seja, envolve ar, água, terra, recursos naturais, flora, fauna, os seres humanos e suas inter-relações (TIBOR, 1996).

Nesse contexto, organizações que pretendam obter credibilidade e aceitação mediante a sociedade precisam responsabilizar-se pelos impactos de suas atividades sobre meio e implantar ações para amenizá-los (DRUCKER, 1997). Para auxiliar os administradores nessa difícil tarefa, a Confederação Nacional da Indústria criou o Sistema de Gestão Ambiental (SGA). Esse sistema requer planejamento, direção, controle, alocação de recursos e demais ações que possam contribuir para redução ou eliminação dos impactos causados por ações humanas, o que exige comprometimento e integração entre as áreas administrativa e operacional (BARBIERI, 2004).

Assim sendo, o administrador deve ser um profissional bem formado, consciente de suas responsabilidades, capaz de buscar tecnologias para minimizar danos socioambientais e evitar procedimentos inadequados, que consumam, esgote ou desperdicem recursos naturais sem nada acrescentar ao produto ou à satisfação do consumidor (VALLE, 1996). Afinal, "a excelência nas práticas referentes ao meio ambiente, segurança, saúde, emprego e comunidade é um dos componentes da estratégia de criação de valor" (KAPLAN; NORTON, 2004, p. 195). Além de contribuir para melhoria da qualidade de vida, a responsabilidade socioambiental das empresas favorece o crescimento econômico da organização, pois, cada vez mais, os consumidores optam por produtos e serviços com certificação de qualidade 


\section{A DEGRADAÇÃO AMBIENTAL NA PERCEPÇÃO DOS ACADÊMICOS DE UM CURSO DE ADMINISTRAÇÃO - UMA LEITURA DO DISCURSO A PRAXIS}

(TENÓRIO, 2006), o que demonstra que esta deve ser considerada como um princípio fundamental à formação de cada administrador.

$\mathrm{Na}$ sua formação, o administrador precisa conhecer princípios da educação ambiental, que é fundamental e deveria ser articulada em todos os níveis do processo educativo, inclusive no ensino superior, que desempenha um importante papel na formação dos profisssionais para o mercado (DAMBROWSKI, 2006). Para tornar-se um profissional competente, o acadêmico precisa conhecer a importância da gestão ambiental, discutir os problemas que envolvem o tema e, ainda, compreender as relações econômicas, políticas, sociais e culturais que influenciam a relação entre humanidade e natureza. Se bem conduzido, esse debate pode levar $\mathrm{o}$ acadêmico a refletir sobre o modelo de desenvolvimento econômico-social vigente, pautado no consumo desenfreado e no desperdício dos recursos naturais (VARGAS; RIBEIRO, 2002).

Todavia no Brasil, estas discussões ainda são bastante superficiais ou inexistentes na academia. Prova disso é o conteúdo das Diretrizes Curriculares Nacionais do curso de graduação em Administração e a Resolução do Conselho Federal de Administração n ${ }^{\circ} 4$, de 13/07/2005, que sugerem os seguintes campos de formação:

a) conteúdos de formação básica: relacionados à antropologia, sociologia, filosofia, psicologia, ética profissional, política, comportamento, economia, contabilidade, ciências jurídicas, tecnologias da comunicação e informação;

b) conteúdos de formação profissional: envolvem teorias da administração e das organizações, administração de recursos humanos, mercado, marketing, materiais, produção, logística, sistemas de informação, planejamento estratégico, serviços; finanças e orçamento;

c) conteúdos de estudos quantitativos e suas tecnologias: abrange pesquisa operacional, modelos matemáticos e estatísticos, teoria dos jogos e aplicação de estratégias, tecnologias e procedimentos que contribuam para o aprimoramento da administração;

d) conteúdos de formação complementar: estudos opcionais e interdisciplinares para o enriquecimento do perfil do formando.

Observa-se que as discussões sobre a temática ambiental não esta contemplada entre os conteúdos exigidos pela regulamentação nacional. Nesse sentido, a inclusão, ou não, de questões relativas a esse tema fica a critério do corpo docente que elabora os projetos dos cursos de administração. 


\section{A DEGRADAÇÃO AMBIENTAL NA PERCEPÇÃO DOS ACADÊMICOS DE UM CURSO DE ADMINISTRAÇÃO - UMA LEITURA DO DISCURSO A PRAXIS}

\section{METODOLOGIA DE PESQUISA}

Esta pesquisa caracteriza-se como descritiva e exploratória. Descritiva porque visa apresentar as características de um fenômeno e exploratória porque se propõe a conhecê-lo, embora, quase não haja informações sobre ele (RICHARDSON, 1989). A adoção destas metodologias deu-se ao fato do objeto de estudo, perante a realidade dos acadêmicos do município de Francisco Beltrão/PR, ser desconhecido na realidade investigada, apresentando várias vertentes que precisam ser descritas para que promovam novas pesquisas sobre a temática.

Francisco Beltrão é um município localizado no sudoeste do estado do Paraná, oficialmente fundado em dezembro de 1952. Segundo estimativa do IBGE, possui uma população de 75.517 habitantes. Em suas atividades primárias, na agricultura as duas principais culturas são a soja e o milho, na pecuária as principais atividades são a bovinocultura, a suinocultura, a avicultura, a produção de leite, de mel e de ovos de galinha e codorna; na indústria extrativista a produção mineral se concentra basicamente em dois tipos de produtos, argila e pedra-brita (basalto). No setor secundário destacam-se o pólo de confecções de vestuário, com mais de 100 empresas do ramo, o setor moveleiro, o setor de metal-leve, além do setor da agroindústria (PREFEITURA MUNICIPAL DE FRANCISCO BELTRÃO/PR, 2008).

No que se refere à vegetação as árvores nativas mais comuns são o Pinheiro-do-Paraná, Angico, Cedro, Ipê, Cerejeira entre outras. Nos últimos anos extensas áreas cobertas por Eucaliptos e Pinus vêm sido plantadas, sendo que estas duas espécies representam duas das principais espécies vegetais encontradas no município. (PREFEITURA MUNICIPAL DE FRANCISCO BELTRÃO/PR, 2008).

A população desta pesquisa foi amparada em Malhotra (2001) que afirma que uma população é a soma de todos os elementos que compartilham um conjunto de características comuns. Neste caso, a população estudada foi composta por todos os 278 acadêmicos matriculados no curso de Administração do campus de Francisco Beltrão/PR, da Universidade Paranaense (UNIPAR) no ano de 2008. Porém, destes somente 201 (Gráfico 1) acadêmicos participar desta pesquisa. 


\section{A DEGRADAÇÃO AMBIENTAL NA PERCEPÇÃO DOS ACADÊMICOS DE UM CURSO DE ADMINISTRAÇÃO - UMA LEITURA DO DISCURSO A PRAXIS}

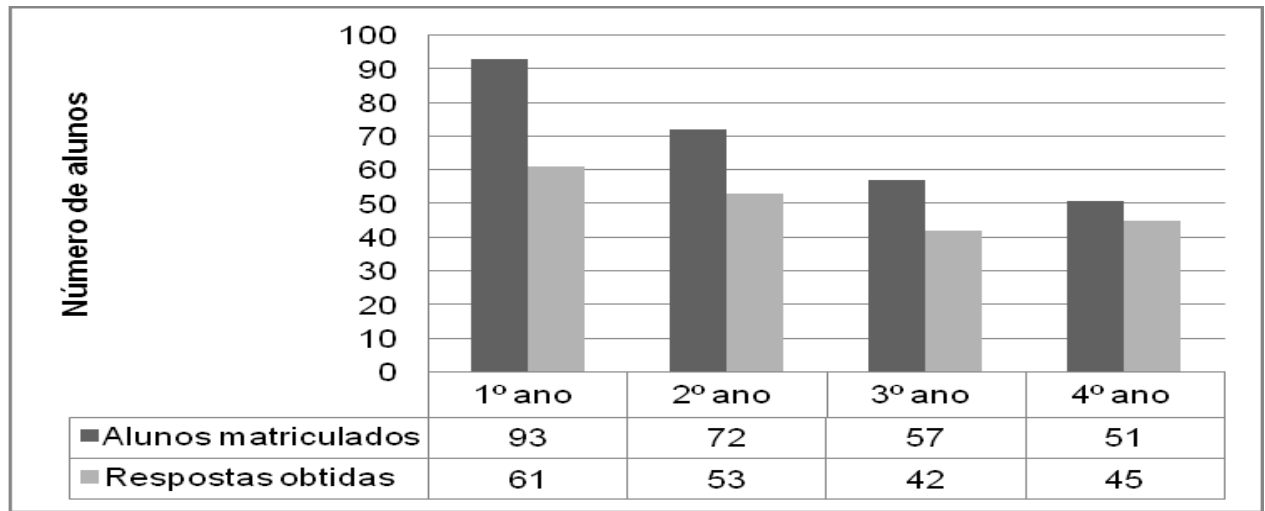

Gráfico 1 População do curso de administração da UNIPAR Fonte: Dados da pesquisa

O procedimento de coleta de dados envolveu uma analise dos documentos dos planos de ensino das disciplinas do curso de administração e aplicação de questionário, com perguntas abertas e fechadas, aos 201 acadêmicos do $1^{\circ}, 2^{\circ}, 3^{\circ}$ e $4^{\circ}$ ano do curso de Administração. Após a coleta dos dados, os questionários foram tabulados no LHStat, um software que gera mapas fatoriais que, segundo Pereira (1999), permitem estabelecer relações entre os resultados. Nesses mapas, a importância de cada eixo é medida pela contribuição da inércia e seu autovalor. Os vetores próximos ao eixo 1 são de atributos de forte correlação positiva, os próximos ao eixo 2 também têm representação significativa, porém, em menor proporção. (LOESCH; HOELTGEBAUM, 2005).

Empregou-se também a análise em componentes principais (ACP), uma técnica de estatística multivariada que permite sintetizar informações de um grande número de variáveis (HAIR et al, 2005). As percepções dos acadêmicos foram avaliadas pela matriz de componentes contidas no intervalo [-1 a +1] (HAIR et al., 2005). Ao final fez-se a análise dos planos e das percepções para que houvesse uma ordenação dos dados em direção a resposta dos objetivos desta pesquisa.

\section{A PERCEPCAO E PRAXIS DOS ACADÊMICOS EM RELAÇÃO À DEGRADAÇÃO AMBIENTAL NO MUNICIPIO}

Questionados sobre as atitudes tomadas em relação à degradação ambiental em Francisco Beltrão/PR, conforme se pode observar no mapa fatorial 1, 20 dos 45 acadêmicos do quarto ano de Administração demonstraram propensão a "orientar pessoas envolvidas" sobre os riscos e métodos preventivos. Nas demais turmas pesquisadas, essa propensão se 


\section{A DEGRADAÇÃO AMBIENTAL NA PERCEPÇÃO DOS ACADÊMICOS DE UM CURSO DE ADMINISTRAÇÃO - UMA LEITURA DO DISCURSO A PRAXIS}

mostrou menos freqüente, sendo demonstrada por 16 dos 61 acadêmicos do primeiro ano, 10 dos 53 do segundo e 4 dos 42 acadêmicos do terceiro.

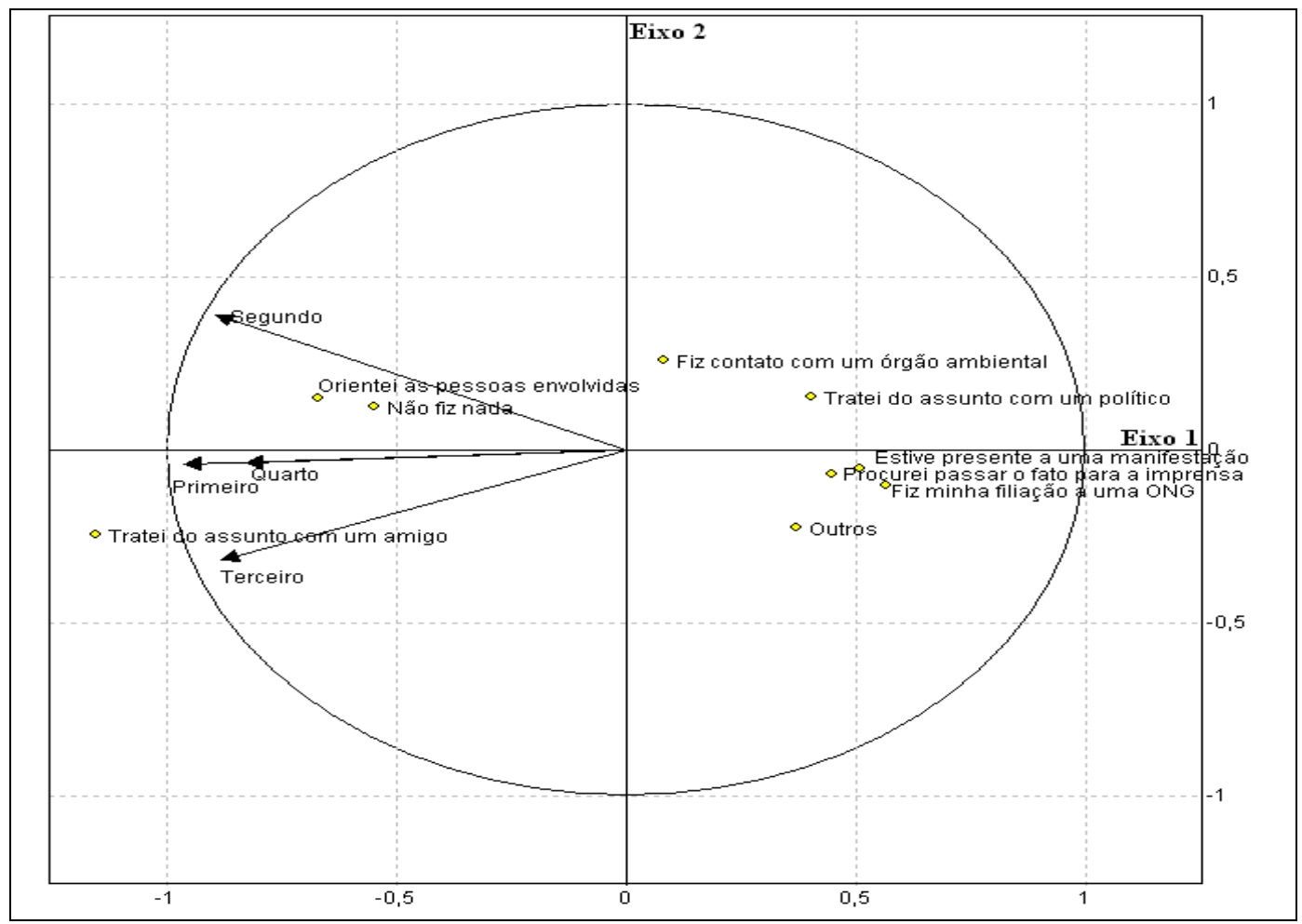

Mapa Fatorial 1 Atitudes em relação à degradação ambiental Fonte: Dados da pesquisa

O mapa fatorial 1 também demonstra que a opção "não fez nada" decresce de $29,51 \%$ no primeiro ano para: $22,64 \%$ no segundo, $21,44 \%$ no terceiro e $8,89 \%$ no quarto. Essa regressão pode ser explicada pelo fato do acadêmico tornar-se mais crítico com o decorrer do curso. A opção "tratei do assunto com um amigo" foi selecionada por: 20 dos 42 acadêmicos do terceiro ano, 20 dos 61 do primeiro, 14 dos 45 do quarto e 13 dos 53 do segundo. As demais foram menos citadas, exceto "fiz contato com um órgão ambiental" mencionada por $18,87 \%$ dos acadêmicos do segundo ano.

$\mathrm{Na}$ análise das coordenadas das atitudes dos acadêmicos em relação à degradação ambiental em Francisco Beltrão/PR, a tabela 1 demonstra que a nuvem de pontos é explicada em uma proporção de $79,1 \%$ no eixo $1 ; 6,4 \%$ no eixo 2 ; e $11,80 \%$ no eixo 3 . Somados, esses eixos representam $97,3 \%$ das respostas.

Tabela 1 Autovalores e inércias das atitudes em relação à degradação ambiental 


\begin{tabular}{cccc|}
$\begin{array}{c}\text { NÚMERO DO EIXO } \\
\text { PRINCIPAL }\end{array}$ & AUTOVALORES & $\begin{array}{c}\text { \% INÉRCIA } \\
\text { TOTAL }\end{array}$ & $\begin{array}{c}\text { \% DE INÉRCIA } \\
\text { ACUMULADA }\end{array}$ \\
\hline 1 & 3,1631 & 79,1 & 79,1 \\
2 & 0,2564 & 6,4 & 85,5 \\
3 & 0,4710 & 11,8 & 97,3 \\
4 & 0,1095 & 2,7 & 100,0 \\
\hline
\end{tabular}

Fonte: Dados da pesquisa

Tabela 2 Estatísticas e coordenadas das atitudes em relação à degradação ambiental

\begin{tabular}{ccccccc} 
VARIÁVEL & MÉDIA & $\begin{array}{c}\text { DESVIO } \\
\text { PADRÃO }\end{array}$ & $\begin{array}{c}\text { \% COEFICIENTE } \\
\text { PADRÃO }\end{array}$ & EIXO 1 & EIXO 2 & EIXO 3 \\
$\begin{array}{c}\text { Primeiro } \\
\text { ano }\end{array}$ & 11,1111 & 13,1087 & 118,00 & $-0,959$ & $-0,041$ & 0,04 \\
$\begin{array}{c}\text { Segundo } \\
\text { ano }\end{array}$ & 11,1111 & 9,5571 & 86,00 & $-0,89$ & 0,39 & $-0,221$ \\
$\begin{array}{c}\text { Terceiro } \\
\text { ano }\end{array}$ & 11,1111 & 14,4188 & 129,80 & $-0,879$ & $-0,318$ & $-0,338$ \\
Quarto ano & 11,1111 & 14,9606 & 134,60 & $-0,823$ & $-0,035$ & 0,554 \\
\hline
\end{tabular}

Fonte: Dados da pesquisa

De acordo com a tabela 2, as coordenadas do eixo 1 apresentam uma correlação de $79,1 \%$ entre as quatro turmas pesquisadas no que concerne às opções "orientei as pessoas envolvidas"; "não fiz nada" e "tratei do assunto com um amigo". No eixo 2, 6,4\% $(0,39)$ dos acadêmicos do segundo ano afastaram-se do grupo por responder "fiz contato com um órgão governamental". No eixo 3,11,8\% dos acadêmicos do quarto ano escolheram a alternativa “estive presente em uma manifestação". A somatória desses eixos corresponde a 97,30\% das atitudes declaradas pelos acadêmicos. Os 2,70\% restantes são explicados pelas ações: "tratei do assunto com um político"; "procurei passar o fato para a imprensa"; "filiei-me a uma ONG" etc.

Conforme o mapa fatorial 2, 71,11\% dos acadêmicos do quarto ano, 63,93\% do primeiro, $58,49 \%$ do segundo e $57,49 \%$ do terceiro consideram a "sociedade em geral" como principal responsável pela degradação do meio ambiente em Francisco Beltrão/PR. 


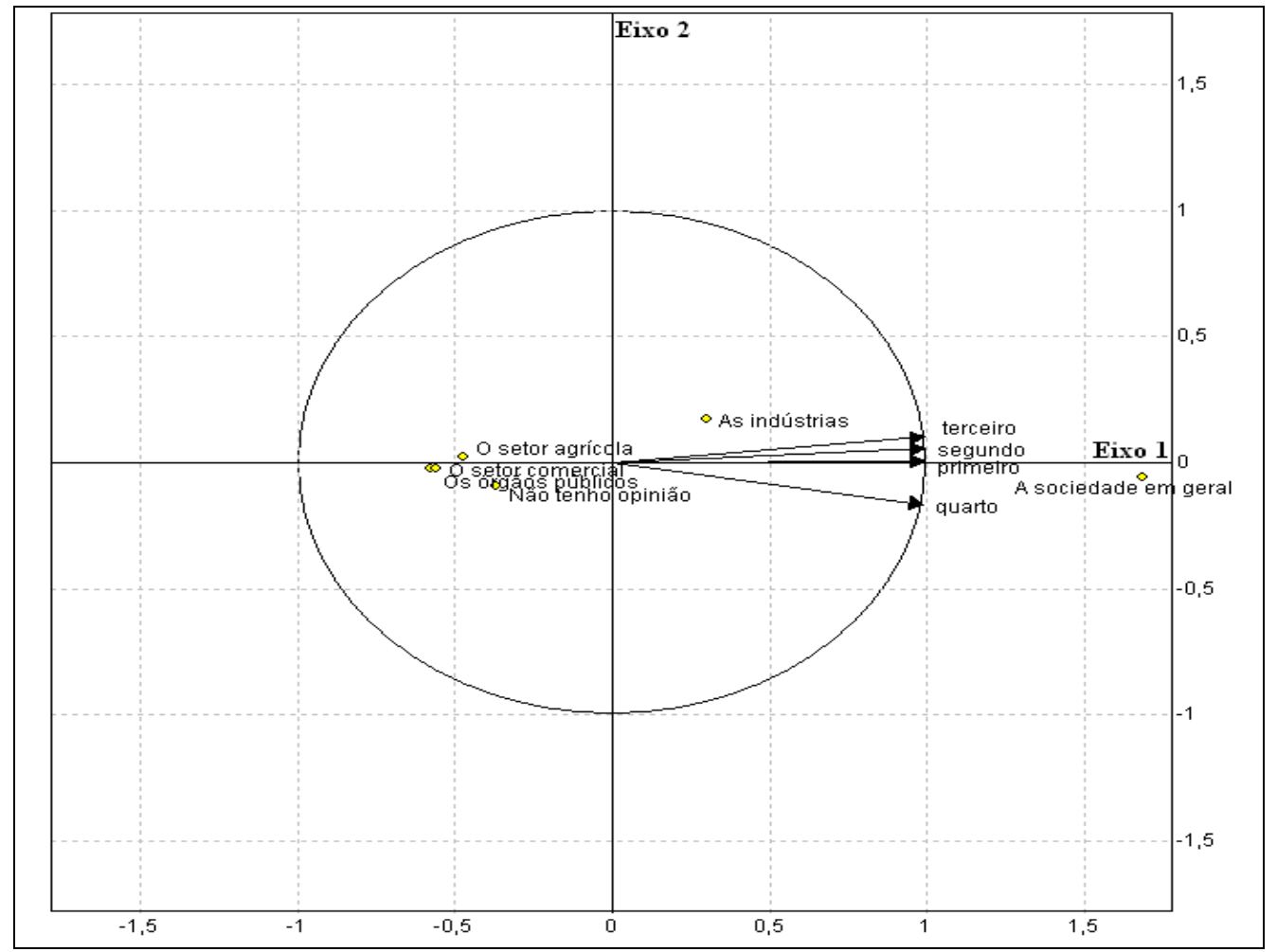

Mapa Fatorial 2 Principais responsáveis pela degradação ambiental Fonte: Dados da pesquisa

Destaca-se que cerca de 30\% dos acadêmicos do primeiro, segundo e terceiro ano, em proporções semelhantes, citaram também "as indústrias" como responsáveis pela degradação do meio ambiente. Em contrapartida, "o setor agrícola"; "o setor comercial; "os órgãos públicos" e "não tenho opinião" quase não são mencionados pelos acadêmicos pesquisados.

Tabela 3 Autovalores e inércias dos responsáveis pela degradação ambiental

\begin{tabular}{cccc}
$\begin{array}{c}\text { NÚMERO DO EIXO } \\
\text { PRINCIPAL }\end{array}$ & AUTOVALORES & $\begin{array}{c}\text { \% INÉRCIA } \\
\text { TOTAL }\end{array}$ & $\begin{array}{c}\text { \% DE INÉRCIA } \\
\text { ACUMULADA }\end{array}$ \\
1 & 3,9331 & 98,3 & 98,3 \\
2 & 0,0434 & 1,1 & 99,4 \\
3 & 0,0225 & 0,6 & 100,0 \\
\hline
\end{tabular}

Fonte: Dados da pesquisa.

$\mathrm{Na}$ análise das coordenadas das opiniões dos acadêmicos sobre quem são os responsáveis pela degradação do meio ambiente em Francisco Beltrão/PR, a tabela 3 demonstra que a nuvem de pontos é explicada em uma proporção de 98,3\% no eixo 1, 1,1\% no eixo 2 e apenas $0,6 \%$ no eixo 3 . Somados, esses eixos representam $100 \%$ das respostas. 
Tabela 4 Estatísticas e coordenadas dos responsáveis pela degradação ambiental

\begin{tabular}{ccccccc} 
VARIÁVEL & MÉDIA & $\begin{array}{c}\text { DESVIO } \\
\text { PADRÃO }\end{array}$ & $\begin{array}{c}\text { \% COEFICIENTE } \\
\text { PADRÃO }\end{array}$ & EIXO 1 & EIXO 2 & EIXO 3 \\
$\begin{array}{c}\text { Primeiro } \\
\text { ano }\end{array}$ & 16,6667 & 22,3840 & 134,30 & 0,993 & 0,006 & 0,116 \\
$\begin{array}{c}\text { Segundo } \\
\text { ano }\end{array}$ & 16,6667 & 21,0496 & 126,30 & 0,994 & 0,057 & $-0,092$ \\
$\begin{array}{c}\text { Terceiro } \\
\text { ano }\end{array}$ & 16,6667 & 20,2949 & 121,80 & 0,994 & 0,106 & 0,001 \\
Quarto ano & 16,6667 & 25,2637 & 151,60 & 0,985 & $-0,17$ & $-0,026$ \\
\hline
\end{tabular}

Fonte: Dados da pesquisa

A tabela 4 demonstra que existe uma correlação de 98,3\% entre as quatro turmas pesquisadas no que tange a opção "sociedade em geral". No eixo 2, 1,1\% do terceiro ano afasta-se do grupo ao considerar "as indústrias". No eixo 3 , representando apenas $0,6 \%$ do primeiro ano apontam o "setor comercial" como responsável pela degradação do meio ambiente. A somatória desses eixos corresponde a 100,0\% das opiniões dos acadêmicos.

De acordo com o mapa fatorial 3, quando questionados sobre quem são os principais envolvidos com a proteção do meio ambiente em Francisco Beltrão/PR, significativa parte dos respondentes citou “órgãos públicos”. Essa opção foi selecionada por 25 dos 61 acadêmicos do primeiro ano, 15 dos 42 do terceiro, 13 dos 53 do segundo e 6 dos 45 acadêmicos do quarto ano.

Nesta questão, chama atenção o percentual de respondentes que escolheu a alternativa "não tenho opinião", no caso, 42,87\% dos acadêmicos do terceiro ano, 40,0\% do quarto, $37,74 \%$ do segundo e $27,87 \%$ do primeiro. A "sociedade em geral" foi considerada responsável por $14,75 \%$ dos acadêmicos do primeiro ano e por $15,09 \%$ do segundo. As opções menos selecionadas pelos acadêmicos foram "setor agrícola", “indústrias", "setor comercial"'. 


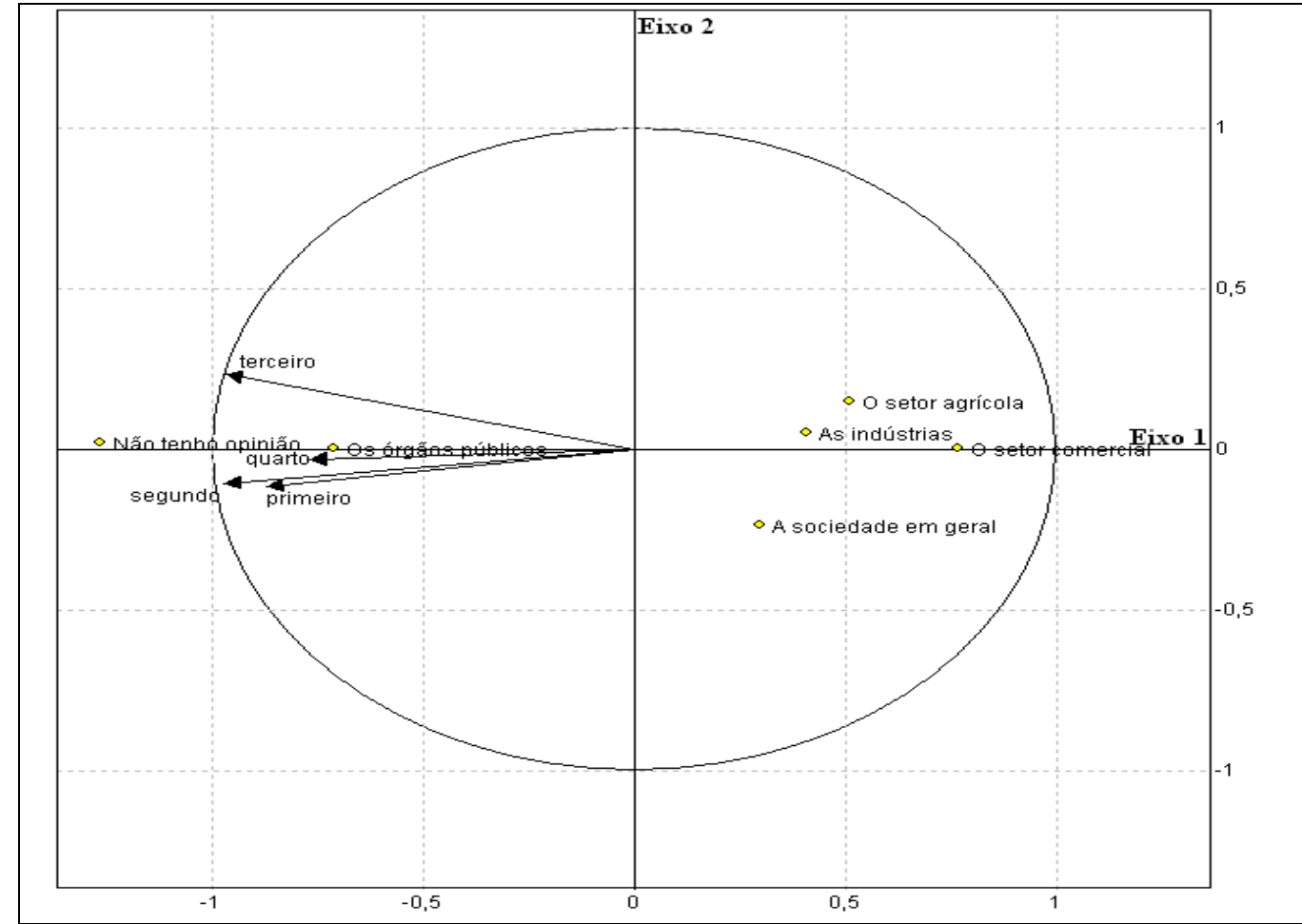

Mapa Fatorial 3 Principais envolvidos com a proteção ambiental Fonte: Dados da pesquisa

Tabela 5 Autovalores e inércias dos envolvidos com a proteção ambiental

\section{NÚMERO DO EIXO}

PRINCIPAL

1

2

3

4
AUTOVALORES

3,1979

0,0809

0,0941

0,6271

\section{\% INÉRCIA} TOTAL 79,9

2,0

2,4

15,7
\% DE INÉRCIA

ACUMULADA

79,9

82,0

84,3

Fonte: Dados da pesquisa

$\mathrm{Na}$ análise das coordenadas das opiniões dos acadêmicos sobre os principais envolvidos com a preservação do meio ambiente em Francisco Beltrão/PR, a tabela 5 demonstra que a nuvem de pontos é explicada em uma proporção de 79,9\% no eixo $1,2,0 \%$ no eixo 2 e $2,4 \%$ no eixo 3. Somados, estes eixos representam $84,3 \%$ das respostas dos acadêmicos.

Na tabela 6, observa-se uma correlação de 79,9\% entre as quatro turmas pesquisadas no que tange as opções "órgãos públicos" e "não tenho opinião". No eixo 2, 2,0\% dos acadêmicos mencionam o "setor agrícola". No terceiro eixo, 2,4\% dos acadêmicos do segundo ano citam o "setor comercial". Os acadêmicos pesquisados não consideram a 
"sociedade em geral" e as "indústrias" como responsáveis pela preservação ambiental em Francisco Beltrão/PR.

Tabela 6 Estatísticas e coordenadas dos envolvidos com a proteção ambiental

\begin{tabular}{c|c|c|c|c|c|c}
\hline VARIÁVEL & MÉDIA & $\begin{array}{c}\text { DESVIO } \\
\text { PADRÃO }\end{array}$ & $\begin{array}{c}\text { \% COEFICIENTE } \\
\text { PADRÃO }\end{array}$ & EIXO 1 & EIXO 2 & EIXO 3 \\
\hline $\begin{array}{c}\text { Primeiro } \\
\text { ano }\end{array}$ & 16,6667 & 13,6623 & 82,00 & $-0,867$ & $-0,115$ & $-0,158$ \\
\hline $\begin{array}{c}\text { Segundo } \\
\text { ano }\end{array}$ & 16,6667 & 11,2918 & 67,80 & $-0,967$ & $-0,106$ & 0,231 \\
\hline $\begin{array}{c}\text { Terceiro } \\
\text { ano }\end{array}$ & 16,6667 & 16,5561 & 99,30 & $-0,964$ & 0,235 & 0,009 \\
\hline Quarto ano & 16,6667 & 11,8798 & 71,30 & $-0,763$ & $-0,033$ & $-0,124$ \\
\hline
\end{tabular}

Fonte: Dados da pesquisa.

Conforme demonstra o mapa fatorial 4, quando questionados em relação às fontes confiáveis de informação sobre as ações praticadas pelas empresas de Francisco Beltrão/PR em prol do meio ambiente, acadêmicos do primeiro ao quarto ano destacaram "materiais de divulgação elaborados pela própria empresa" e "contato com um colaborador da empresa".

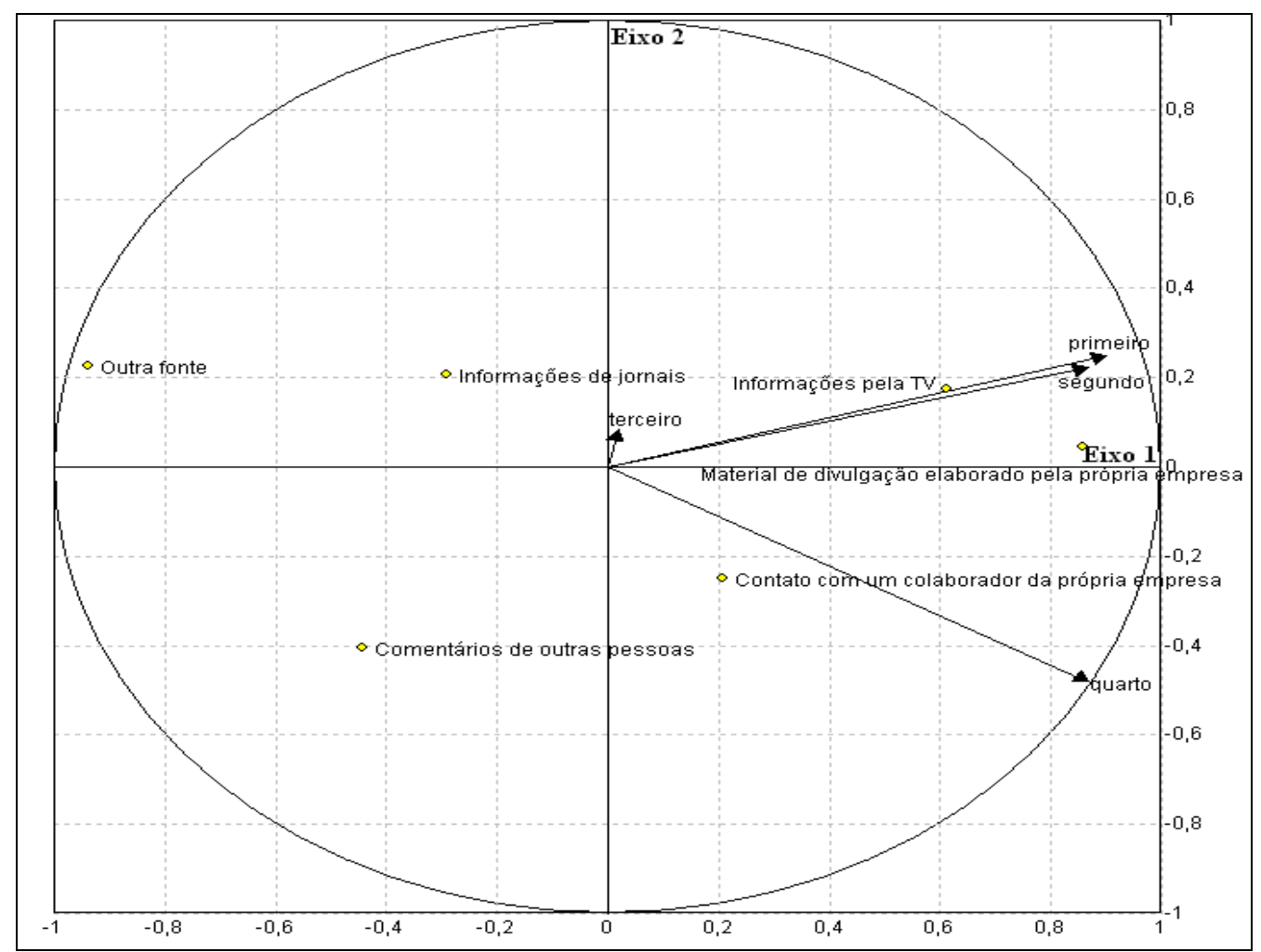

Mapa fatorial 4 Fontes de informação sobre as ações em prol do meio ambiente Fonte: Dados da pesquisa. 


\section{A DEGRADAÇÃO AMBIENTAL NA PERCEPÇÃO DOS ACADÊMICOS DE UM CURSO DE ADMINISTRAÇÃO - UMA LEITURA DO DISCURSO A PRAXIS}

Ressalta-se ainda que, nesta questão, $42,86 \%$ dos acadêmicos do terceiro ano mencionaram "informações em jornais" e 39,94\% do primeiro ano "informações fornecidas pela televisão". A opção "comentários de outras pessoas" e "outras fontes" foram pouco citadas.

Tabela 7 Autovalores e inércias de fontes de informação confiáveis sobre as ações das empresas em prol do meio ambiente

\begin{tabular}{c|c|c|c}
\hline $\begin{array}{c}\text { NÚMERO DO EIXO } \\
\text { PRINCIPAL }\end{array}$ & AUTOVALORES & $\begin{array}{c}\text { \% INÉRCIA } \\
\text { TOTAL }\end{array}$ & $\begin{array}{c}\text { \% DE INÉRCIA } \\
\text { ACUMULADA }\end{array}$ \\
\hline 1 & 2,3138 & 57,8 & 57,8 \\
\hline 2 & 0,3525 & 8,8 & 66,7 \\
\hline 3 & 0,212 & 5,3 & 72,0 \\
\hline 4 & 1,1218 & 28,0 & 100,0 \\
\hline
\end{tabular}

Fonte: Dados da pesquisa

$\mathrm{Na}$ análise das coordenadas das fontes de informação - que os acadêmicos consideram confiáveis - sobre as ações praticadas pelas empresas de Francisco Beltrão/PR em prol do meio ambiente, a tabela 7 demonstra que a nuvem de pontos é explicada em uma proporção de $57,8 \%$ no eixo $1,8,8 \%$ no eixo 2 e $5,3 \%$ no eixo 3 . Somados, estes eixos representam $72 \%$ das respostas.

Quadro 8 Estatísticas e coordenadas de fontes de informação sobre as ações das empresas em prol do meio ambiente

\begin{tabular}{c|c|c|c|c|c|c}
\hline VARIÁVEL & MÉDIA & $\begin{array}{c}\text { DESVIO } \\
\text { PADRÃO }\end{array}$ & $\begin{array}{c}\text { \% COEFICIENTE } \\
\text { PADRÃO }\end{array}$ & EIXO 1 & EIXO 2 & EIXO 3 \\
\hline $\begin{array}{c}\text { Primeiro } \\
\text { ano }\end{array}$ & 16,6667 & 12,2807 & 73,7 & 0,866 & 0,223 & 0,305 \\
\hline $\begin{array}{c}\text { Segundo } \\
\text { ano }\end{array}$ & 16,6667 & 14,4283 & 86,6 & 0,900 & 0,249 & $-0,307$ \\
\hline $\begin{array}{c}\text { Terceiro } \\
\text { ano }\end{array}$ & 16,6667 & 14,2210 & 85,3 & 0,020 & 0,083 & 0,158 \\
\hline Quarto ano & 16,6667 & 8,9582 & 53,7 & 0,868 & $-0,483$ & 0,010 \\
\hline
\end{tabular}

Fonte: Dados da pesquisa

A tabela 8 demonstra que no eixo 1 há uma correlação de $57,8 \%$ entre as turmas do primeiro, segundo e quarto ano no que tange a escolha da opção "material divulgado pela própria empresa". As respostas dos acadêmicos do terceiro ano distanciaram-se desta estatística. Analisando-se o eixo 2, percebe-se que $8,8 \%$ dos acadêmicos do primeiro e 


\section{A DEGRADAÇÃO AMBIENTAL NA PERCEPÇÃO DOS ACADÊMICOS DE UM CURSO DE ADMINISTRAÇÃO - UMA LEITURA DO DISCURSO A PRAXIS}

segundo ano consideram importantes as "informações fornecidas pela televisão". No eixo 3, $5,3 \%$ dos acadêmicos do primeiro ano optaram por "materiais divulgados pela própria empresa".

Os acadêmicos foram questionados sobre a abordagem de temas relacionados ao meio ambiente, ambiente natural, gestão ambiental e responsabilidade social em sala de aula. Constatou-se que o curso de Administração da UNIPAR não oferece disciplina específica, no entanto, alguns professores incluem temas relacionados ao meio ambiente em suas disciplinas. O gráfico 2 demonstra que, na percepção dos acadêmicos, os conteúdos relacionados ao meio ambiente têm sido abordados com mais freqüência no primeiro e no quarto ano.

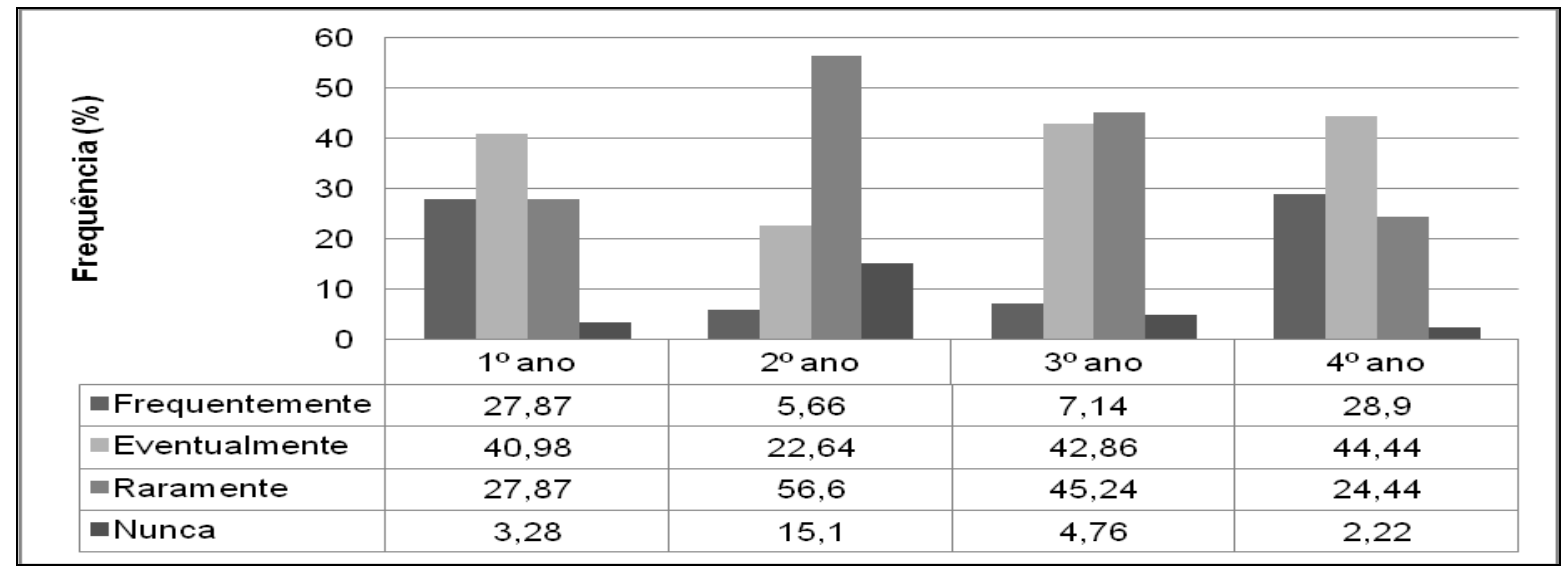

Gráfico 2 Abordagem de conteúdos relacionados ao meio ambiente Fonte: Dados da pesquisa.

Solicitou-se aos respondentes que identificassem as disciplinas nas quais são abordados temas relacionados ao meio ambiente. No primeiro ano, $80,33 \%$ dos acadêmicos citaram a disciplina Noções de Ciências sociais e 6,56\% Língua Portuguesa. No segundo ano, 45,28\% dos acadêmicos mencionaram Noções de Ciências Sociais, 41,51\% Psicologia organizacional e $13,21 \%$ consideraram que não há disciplinas voltadas ao tema. No terceiro ano, 26,19\% indicaram Noções de Ciências Sociais, 71,43\% Administração de Negócios Agropecuários e $2,38 \%$ consideram que não há disciplinas voltadas ao tema. No quarto ano, $93,33 \%$ dos acadêmicos apontaram a disciplina de Tópicos Especiais em Administração e 6,67\% Cultura e Sociedade Brasileira. Analisando-se o plano de ensino das disciplinas citadas pelos acadêmicos pesquisados constou-se que: 


\section{A DEGRADAÇÃO AMBIENTAL NA PERCEPÇÃO DOS ACADÊMICOS DE UM CURSO DE ADMINISTRAÇÃO - UMA LEITURA DO DISCURSO A PRAXIS}

- Noções de Ciências Sociais relaciona conceitos fundamentais de ciências sociais e antropologia à administração e cultura organizacional. Inclui questões ligadas à responsabilidade social das organizações, cultura, sociedade e recursos naturais.

- Língua Portuguesa não apresenta conteúdos diretamente relacionados ao meio ambiente. A disciplina trabalha estrutura e tipologia textual; produção de textos técnicos e científicos e análise de estruturas lingüísticas voltadas à conscientização sobre a natureza sócio-interativa da linguagem no processo de humanização do ser. Acredita-se que, embora não especificados na ementa, alguns textos estudados possam abordar questões ambientais.

- Psicologia Organizacional estuda o comportamento humano, suas implicações no trabalho e apreciação crítica das relações interpessoais nas organizações.

- Administrações de negócios agropecuários aborda conceitos, processos e objetivos de negócios agropecuários nos ambientes rural, industrial, comercial e de serviços. Trata de aspectos relacionados à industrialização e manufatura de produtos agropecuários e desenvolvimento agrícola sustentável.

- Tópicos Especiais em Administração dentre as disciplina analisadas, esta é a que mais aborda temas relacionados ao meio ambiente. Trata de liderança e equipe de trabalho na organização, ética empresarial, responsabilidade social na empresa, ambiente e cultura organizacional.

- Cultura e Sociedade Brasileira estuda os aspectos psicosociais, antropológicoculturais, político-administrativos e econômicos da realidade brasileira; revolução tecnológica, direitos e violência humana.

Analisando-se esses planos de ensino, observa-se que, embora tratem de algumas questões ambientais de maneira superficial e isolada, as disciplinas e conteúdos do curso de Administração da UNIPAR não fornecem subsídios suficientes para que seus acadêmicos possam internalizar a importância da administração comprometida com a conservação ambiental. Em especial, em uma realidade em que os próprios acadêmicos podem perceber os impactos que estão prejudicando o desenvolvimento da região. Alem disso, a universidade, por sua vez, apresenta um posicionamento reativo e lento em direção a discussão e mudança dos problemas atuais do município.

\section{CONSIDERAÇÕES FINAIS}

Com relação à percepção dos acadêmicos do curso de Administração da UNIPAR sobre à degradação do ambiente no município de Francisco Beltrão/PR, infere-se que, embora eles culpem a sociedade em geral e as indústrias pela deterioração dos recursos naturais, a maioria considera o Estado como principal responsável pela conservação, o que, de certa forma, isenta os degradadores de suas responsabilidades. Verifica-se que a cultura paternalista ainda impera 


\section{A DEGRADAÇÃO AMBIENTAL NA PERCEPÇÃO DOS ACADÊMICOS DE UM CURSO DE ADMINISTRAÇÃO - UMA LEITURA DO DISCURSO A PRAXIS}

nas percepções investigadas, uma vez que o Estado é visto como aquele que irá resolver os efeitos de uma sociedade mal esclarecida quanto a sua atitude em relação ao ambiente.

Acredita-se que os respondentes visualizam a sociedade como o "outro" não entendem o sentimento de pertencer, assim não sentem a necessidade de assumir uma postura proativa em relação aos problemas socioambientais. Significativa parte dos acadêmicos pesquisados declara que faz pouco ou nada diante do reconhecimento de problemas da degradação ambiental no município.

Constata-se, ainda, que a maioria dos respondentes - ingenuamente - considera as informações divulgadas pela empresas da região, como uma fonte confiável. Vale lembrar, no entanto, que muitas empresas utilizam a divulgação de ações sociais como um artifício para promover a própria imagem, o que não é suficiente para garantir a veracidade das informações (CRESPO, 2003).

No que diz respeito à educação ambiental, observou-se que o curso de Administração da UNIPAR não oferece nenhuma disciplina específica, no entanto, alguns professores afirmam que incluem temas relacionados ao ambiente no plano de ensino, segundo os acadêmicos, principalmente no primeiro e quarto ano do curso. Este fato foi observado na análise dos planos de ensino, evidenciando um pequeno movimento em prol de uma mudança. Dentre as disciplinas que abordam temas relacionados ao ambiente, os acadêmicos destacaram: em ordem decrescente, Tópicos Especiais em Administração, Noções de Ciências sociais, Administração de Negócios Agropecuários, Psicologia organizacional, Cultura e Sociedade Brasileira e Língua Portuguesa. Todavia, afirmaram que a discussão ainda é muito superficial.

No que se refere à influência do curso sobre a percepção dos acadêmicos em relação ao ambiente, destaca-se que os respondentes do quarto ano apresentam mais propensão a encaminhar providências quando reconhecem um problema de ordem socioambiental, o que sugere haver desenvolvimento do senso crítico no decorrer do curso. Ou ainda, mais maturidade diante dos fatos locais.

Esses resultados demonstram que os cursos de graduação em Administração precisam adequar seus currículos à realidade contemporânea vinculando as discussões aos locais em que os acadêmicos estão inseridos. Principalmente, reforçando o fenômeno da relação entre empresa e ambiente. Ademais, considera-se que os modelos clássicos de administração que não consideravam esse elemento, não foram suficientes para atender às demandas por 
conservação e eficiência. Por isso, os novos administradores precisam possuir um comportamento diferenciado e comprometido com este desafio cada vez mais emergente na vida das empresas e, conseqüentemente mais cobrado pela sociedade e pelo mercado.

Por fim, ressalta-se que como esta pesquisa apresenta um recorte sobre uma parte da realidade, recomenda-se que novos estudos sejam realizados para ampliar esta discussão, especialmente para contribuir com o desenvolvimento do município de Francisco Beltrão/PR.

\section{REFERÊNCIAS}

BARBIERI, J. C. Gestão ambiental empresarial: conceitos, modelos e instrumentos. São Paulo: Ed. Saraiva, 2004.

BRASIL. Resolução n. ${ }^{\circ}$ 4, de 7 de julho de 2005. Diretrizes Curriculares Nacionais do curso de Graduação em Administração. Relator: Edson de Oliveira Nunes. Publicado D.O.U Diário Oficial da União, Brasília, 19 jul. 2005. Disponível em: http://www.cfa.org.br/download/ Res_2005_n04.pdf. Acesso em: 06 de agosto de 2008.

CAPRA, F. In: TRIGUEIRO, André (Coord.). Meio ambiente no século 21: 21 especialistas falam da questão ambiental nas suas áreas de conhecimento. Rio de Janeiro: Sextante, 2003.

\section{CONSELHO FEDERAL DE ADMINSITRAÇÃO. Código de Ética Profissional do}

Administrador, 2008. (Aprovado pela Resolução Normativa CFA no 353, de 9 de abril de 2008). Disponível Em:

http://www.cfa.org.br/arquivos/selecionaitem.php? $p=$ selecionaitem.php\&coditem=63.

Acesso: 25 de agosto de 2008.

CRESPO, S. In: TRIGUEIRO, André (Coord.). Meio ambiente no século 21: 21

especialistas falam da questão ambiental nas suas áreas de conhecimento. Rio de Janeiro:

Sextante, 2003.

DAMBROWSKI, A. As questões Ambientais no Ensino de Administração nas Instituições de Ensino Superior de Blumenau, SC. 2006. 81 f. Dissertação (Mestrado em Administração) Centro de Ciências Sociais Aplicadas, Universidade Regional de Blumenau, Blumenau, 2006.

DRUCKER, P. F. Fator humano e desempenho: o melhor de Peter F. Drucker sobre administração. $3^{\circ}$ ed. São Paulo: Pioneira, 1997.

HAIR, JR. et al. Fundamentos de métodos de pesquisa em Administração. São Paulo: Bookman, 2005.

IBAMA - CONSELHO NACIONAL DO MEIO AMBIENTE - RESOLUÇÃO CONAMA No 001, de 23 de janeiro de 1986. Disponível em: http://www.mma.gov.br/port/conama/ 
res/res86/res0186.html. Acesso em 29 de agosto de 2008.

KAPLAN, R. S.; NORTON, D. P. Mapas estratégicos: convertendo ativos intangíveis em resultados tangíveis. $7^{\circ}$ ed. Rio de Janeiro: Campus, 2004.

LOESCH, C.; HOELTGEBAUM, M. Métodos estatísticos multivariados aplicados à economia de empresas. Blumenau: Nova Letra, 2005.

MALHOTRA, N. K. Pesquisa de marketing: uma orientação aplicada. $3^{\circ}$ ed. Porto Alegre: Bookman, 2001.

PEREIRA, Júlio Cesar R. Análise de dados qualitativos: estratégias metodológicas para as ciências da saúde, Humanas e Sociais. São Paulo: Universidade de São Paulo, 1999.

PREFEITURA MUNICIPAL DE MEIO AMBIENTE DE FRANCISCO BELTRÃO/PR. lei n $^{0}$ 2891/2002. Disponível em: http://www.franciscobeltrao.pr.gov.br/legislacao/visualizar. asp?id=250\&t lei=2. Acesso 27 de agosto de 2008 .

RICHARDSON, R. J. Pesquisa social: métodos e técnicas. São Paulo: Atlas, 1989.

SEMA - SECRETARIA DE ESTADO DO MEIO AMBIENTE E RECURSOS HÍDRICOS Cianorte e Francisco Beltrão recebem as Conferências Regionais do Meio Ambiente. Disponível em:

http://www.sema.pr.gov.br/modules/noticias/article.php?storyid=74. Acesso em 29 de agosto de 2008.

TENÓRIO, F. G. (org.). Responsabilidade social empresarial: teoria e prática. $2^{\circ}$ ed. Rio de Janeiro: FGV, 2006.

TIBOR, T. ISO 14000. São Paulo: Futura, 1996.

VARGAS, H. C.; RIBEIRO, H. (org). Novos instrumentos de gestão ambiental urbana. São Paulo: Edusp, 2002.

VALLE, C. E. Qualidade ambiental: o desafio de ser competitivo protegendo o meio ambiente. São Paulo: Pioneira, 1996.

VALLE, C. E. Qualidade ambiental: ISO 14000. São Paulo: SENAC, 2002. 


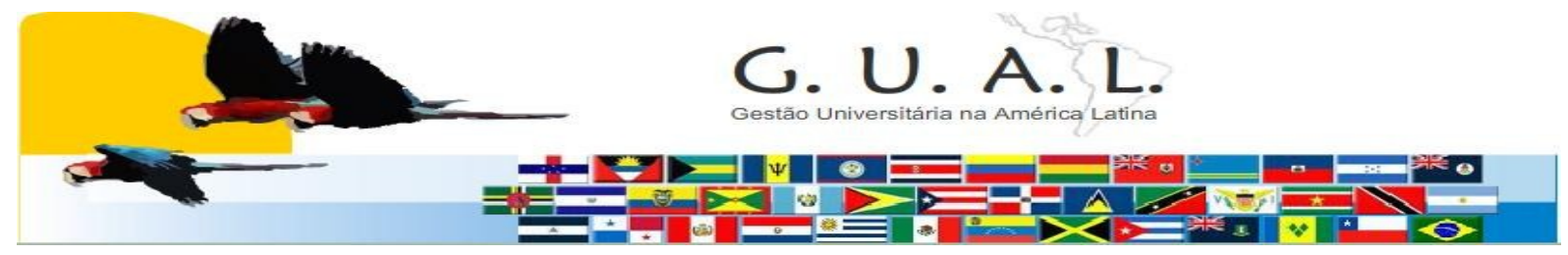

ISSN 1983-4535

\title{
ENVIRONMENTAL DEGRADATION IN PERCEPTION OF SCHOLARS FROM A COURSE OF DIRECTORS - READING A SPEECH PRAXIS
}

\author{
Jucelia Appio Tibola, Master \\ Universidade Positivo - UP \\ juceliaappio@yahoo.com.br \\ Marialva Tomio Dreher, Doctor \\ Universidade Regional de Blumenau - FURB \\ marialva@furb.br \\ Paula Regina Zarelli Rocha, Specialist \\ Universidade Estadual do Oeste do Paraná - UNIOESTE \\ przarelli@hotmail.com
}

\begin{abstract}
This paper analyzes the students' perception of Management students at the University Paranaense (UNIPAR), Francisco Beltrão/PR, in relation to city environmental degradation and identifies subjects' opinion that raising awareness of this topic. To do this research, we reviewed the teaching plans and applied a questionnaire to 201 students. It was found that, on the one hand, most students preserves the traditional thinking that the state is responsible for environmental preservation, on the other hand, most students consider the wider society as primarily responsible for degradation. It was noted also that the course curriculum needs to broaden the discussion of issues related to environmental management, sustainable development, social responsibility and other matters, which are consistent with the contemporary reality.
\end{abstract}

Keywords: Environment. Business course. Environmental management. 